\title{
THE NEED FOR INTENSIVE NURSING CARE
}

\author{
BY \\ S. A. G. GARRETT, S.R.N., AND R. L. STEPHENSON, S.R.N \\ Sister Tutors, St Thomas' Hospital \\ AND \\ W. W. HOLLAND AND I. Z. ROTH \\ Department of Clinical Epidemiology and Social Medicine, St Thomas' Hospital Medical School
}

In order to be able to assess the need for intensive nursing care (INC) in a general teaching hospital of 468 beds ( 230 surgical; 196 medical; 42 paediarric), a survey was conducted during the period July 1, 1963 , to June 30,1964 . Obstetric, gynaecological, psychiatric, and post-operative recovery beds were excluded from the survey.

\section{METHOD}

Before the start of the survey, the purpose and method was explained in detail to each of the ward sisters involved. Daily ward visits were then made by two nursing sisters, one a tutor and the other a clinical instructor, who had freedom to visit the wards whenever they wished.

For the purpose of the survey, the hospital was divided into five approximately equal blocks of 75 beds. One block of wards was visited each day. The survey was carried out on seven days a week; one sister was always present on Saturday and the wards concerned noted any case requiring INC on a Sunday and these after scrutiny were recorded on Monday.

By virtue of their experience, the two Sister Tutors were completely familiar with the type of work and work-load in each of the wards surveyed. They were thus able to assess objectively the required patient care.

The criteria for needing INC were defined at the start by a combined committee of representatives of the medical, nursing, and administrative staff. The criteria were grouped into the following clinical categories:

(A) Unconsciousness

Totally dependent upon nursing staff and needing medical supervision, but not including terminal illness.

\section{(B) Paralysis}

Totally dependent upon nursing staff, and possibly needing medical supervision because of the paralysis, e.g. tracheostomy.

(C) Burns 70 per cent.

In urgent need of resuscitation involving constant medical and nursing care.

(D) Multiple Injuries

Requiring immediate resuscitation and urgent surgery and therefore totally dependent upon the nursing and medical staff.

(E) Respiratory Failure

Requiring resuscitation and immediately fully dependent upon the nursing and medical staff until adequate ventilation was established and the patient acclimatized to his condition, i.e. the respirator.

$(F)$ Acute Renal Failure (due to poisoning)

Requiring immediate mechanical aid (dialysis) and subsequent resuscitation and observation.

\section{(G) Hypotension due to Haemorrhage}

Requiring astute and continuous observation by nursing and medical staff, plus care and treatment.

It should be appreciated that many patients qualified for more than one category, e.g.

(A) Unconsciousness could include

(B) Paralysis could include

C. D. E. F

(C) Burns 70 per cent. could include

(D) Multiple injuries could include

(E) Respiratory failure could include

(F) Renal failure could include

A. D. E

A. D. E. F

A. B. C. E. F

A. B

(G) Hypotension could include severe hypotension from whatever cause

The main criteria for assessment of the patient's needs were: 
(1) Total dependency upon nursing and/or medical staff or both, with all that this entails.

(2) The need for continuous and unremitting observations which calls for frequent, accurate, and perhaps continuous recording.

It should be noted that patients in this hospital are at present nursed in traditional 30-bed Nightingale wards, with one single room frequently used for the seriously-ill patients. Once a patient no longer fulfils the criteria for INC, he can, if necessary, be observed by the nursing staff frequently, albeit not continuously, if he is returned to the ward. In addition, it must be remembered that in a teaching hospital there is a greater number of staff on duty or available at any one time than would perhaps be possible elsewhere.

In order to obtain a true estimate of the type of clinical cases present in the hospital during the survey, details were obtained on a random one-in-ten sample of all patients discharged during the same period, namely July 1,1963 , to June 30,1964 , using the terminal digit of the Hospital Number for selecting the sample.

\section{RESULTS}

During the year there were 10,790 discharges from the medical, surgical, and paediatric wards of St. Thomas' Hospital, and 1,079 discharges were recorded by our 10 per cent. sample survey of discharges during this period. Tests will be carried out to determine the representativeness of this sample by comparing it with the 10 per cent. sample of discharges collected for the Registrar General's Hospital In-Patient Inquiry.

\section{(1) NUMBER OF BEDS REQUIRED FOR INTENSIVE NURSING CARE}

During the period of the survey 75 patients were found to require INC on 104 occasions (Table I).

\section{TABLE I}

DISTRIBUTION OF NUMBER OF BEDS REOUIRED FOR INC IN VISITED BLOCKS OF WARDS AND DISTRIBUTION OF PATIENTS REQUIRING INC ON DIFFERENT NUMBERS OF SUCCESSIVE VISITS

\begin{tabular}{c|c|c|c|c|c}
\hline \multirow{2}{*}{$\begin{array}{c}\text { Beds } \\
\text { Required }\end{array}$} & \multicolumn{2}{|c|}{ Days } & \multirow{2}{*}{$\begin{array}{c}\text { No. of } \\
\text { Times } \\
\text { Observed }\end{array}$} & \multicolumn{2}{c}{ Patients Observed } \\
\cline { 2 - 3 } \cline { 5 - 6 } & No. & Per cent. & No. & Per cent. \\
\hline 0 & 285 & 77.87 & 1 & 61 & $81 \cdot 33$ \\
1 & 61 & 16.67 & 2 & 8 & 10.67 \\
2 & 17 & 4.64 & 3 & 2 & 2.67 \\
3 and More & 3 & 0.82 & 4 & 2 & 2.67 \\
& & & 5 & 1 & 1.33 \\
& & & 6 & 0 & 0.00 \\
& & & 7 & 0 & 0.00 \\
& & & 8 & 1 & 1.33 \\
\hline Total & 366 & 100.00 & Total & 75 & $100 \cdot 00$ \\
\hline
\end{tabular}

Obviously, because of the 5-day intervals at which any one ward was visited, some patients requiring INC would not be recorded. Using the information in Table $I$ and considering the 5-day intervals between observations, the distribution of the duration for which INC would be required by those needing this type of care (inlcuding those not observed) was estimated using simple assumptions of the laws of probability involved (see Appendix). Similarly, an estimate of the distribution of duration (in days) of need for INC for those 75 patients observed was calculated, taking into account the estimated distribution of need of all patients and the method of sampling at 5-day intervals. The expected number of patients, totalling to 74 (one patient who was observed on eight occasions has been excluded from this analysis), was then rounded to provide whole numbers. The latter figures and the respective percentages of all 75 patients are presented in Table II together with the estimated duration of need for INC of both those patients observed and those not observed. Thus 29.4 per cent. of all the patients requiring INC would need it for 1 day only, 20.8 per cent would need it for 2 days, and so on. From these calculations, it is further possible to estimate that our sample of patients requiring INC represented 47.8 per cent. of all patients requiring INC*.

TABLE II

ESTIMATED DISTRIBUTION OF DURATION OF NEED FOR INC IN 75 ST. THOMAS' HOSPITAL PATIENTS RECORDED IN THE STUDY AND IN ALL PATIENTS INCLUDING THOSE UNOBSERVED

\begin{tabular}{|c|c|c|c|}
\hline $\begin{array}{l}\text { Duration } \\
\text { of INC } \\
\text { (days) }\end{array}$ & $\begin{array}{c}\text { Estimated No. } \\
\text { of Patients } \\
\text { requiring INC }\end{array}$ & $\begin{array}{l}\text { Percentage of } \\
\text { No. of Patients } \\
\text { requiring INC }\end{array}$ & $\begin{array}{c}\text { Expected Per- } \\
\text { centages of All } \\
\text { (including un- } \\
\text { observed) } \\
\text { Patients } \\
\text { requiring INC }\end{array}$ \\
\hline $\begin{array}{c}0-1 \\
1-2 \\
2-3 \\
3-4 \\
4-5 \\
5-6 \\
6-7 \\
7-8 \\
8-9 \\
9 \text { or More }\end{array}$ & $\begin{array}{r}4 \\
9 \\
12 \\
11 \\
10 \\
8 \\
6 \\
4 \\
3 \\
7(+1)\end{array}$ & $\begin{array}{r}5 \cdot 3 \\
12 \cdot 0 \\
16 \cdot 0 \\
14 \cdot 7 \\
13 \cdot 3 \\
10 \cdot 7 \\
8 \cdot 0 \\
5 \cdot 3 \\
4 \cdot 0 \\
10 \cdot 7\end{array}$ & $\begin{array}{l}29 \cdot 4 \\
20 \cdot 8 \\
14 \cdot 6 \\
10.6 \\
7.0 \\
5 \cdot 2 \\
3.6 \\
2.6 \\
1.8 \\
4.4\end{array}$ \\
\hline Total & $74(+1)$ & $100 \cdot 0$ & $100 \cdot 0$ \\
\hline
\end{tabular}

Using this estimate one may assume that during the 365 days of the survey, a total of $157^{*}$ patients would have required INC, i.e. $1 \cdot 5$ per cent. of all patients discharged. From the table of duration of INC (Table II) it may be calculated that INC was required for 451 " "bed-patient-days" for the entire

- Seo statistical appendix. 
hospital during the period of the survey, i.e. on average $1 \cdot 23$ such beds would be needed on each day.

It has been found that the requirements for INC follow closely those of a Poisson distribution*. Therefore, from Table III it may be seen that if the need for INC is to be satisfied on 95 per cent. of all occasions, four beds will be required for this type of care. It is shown that five beds will be used for INC on only 2 days in the year. However, it should be noted that this conclusion is made on the basis of a "smoothed model" which cannot take into account the case which may require INC for an extended period. In order, therefore, to attempt to satisfy all needs at all times, an upper limit of eight beds* would be required.

TABLE III

ESTIMATED NUMBER OF BEDS OCCUPIED BY PATIENTS REQUIRING INC ASSUMING THE POISSON DISTRIBUTION

\begin{tabular}{|c|c|c|}
\hline Beds Required & Percentage & $\begin{array}{l}\text { Expected Days } \\
\text { in } 1 \text { year }\end{array}$ \\
\hline $\begin{array}{c}0 \\
1 \\
2 \\
3 \\
4 \\
5 \\
\quad 6 \\
7 \text { or More }\end{array}$ & $\begin{array}{r}29.17 \\
35.94 \\
22.14 \\
9.09 \\
2.80 \\
0.69 \\
0.14 \\
0.03\end{array}$ & $\begin{array}{r}106 \cdot 76 \\
131 \cdot 54 \\
81 \cdot 03 \\
33 \cdot 27 \\
10 \cdot 25 \\
2 \cdot 53 \\
0 \cdot 51 \\
0 \cdot 11\end{array}$ \\
\hline Total $\ldots$.. & $100 \cdot 00$ & $366 \cdot 00$ \\
\hline
\end{tabular}

(2) REASON FOR REQUIRING INC

Table IV shows the criteria by which patients were selected for INC. As is evident, the most important cause was unconsciousness (category A) which was present on $65(62 \cdot 5$ per cent.) occasions.

TABLE IV

REASON FOR INC BY DEFINED CATEGORIES

\begin{tabular}{c|c|c}
\hline & \multicolumn{2}{|c}{ Sample of Patients requiring INC } \\
\cline { 2 - 3 } Category & No. & Per cent. \\
\hline A & 32 & $30 \cdot 8$ \\
B & 5 & $4 \cdot 8$ \\
C & 0 & $5 \cdot 8$ \\
E & 4 & $3 \cdot 8$ \\
F & 15 & $14 \cdot 4$ \\
G D & 2 & $1 \cdot 9$ \\
A D & 4 & $3 \cdot 8$ \\
A E & 20 & $1 \cdot 9$ \\
A G & 3 & $2 \cdot 9$ \\
B E & 2 & $1 \cdot 9$ \\
B G & 1 & $1 \cdot 0$ \\
D G & 1 & $1 \cdot 0$ \\
E G & 1 & $4 \cdot 0$ \\
F G & 5 & $1 \cdot 0$ \\
A D E & 1 & $1 \cdot 0$ \\
A D G & 1 & $2 \cdot 9$ \\
A E F & 3 & $1 \cdot 9$ \\
\hline Total .. & 2 & $100 \cdot 0$ \\
\hline
\end{tabular}

- See statistical appendix.

\section{(3) Seasonal Variation}

Table $V$ shows that there is little seasonal variation in the total number of patients discharged, but that there is a marked variation in the requirements for INC, the proportion of patients requiring INC being much higher in the winter than the summer months.

TABLE V

SEASONAL VARIATION IN DISCHARGES FROM HOSPITAL AND PATIENTS REQUIRING INC

\begin{tabular}{|c|c|c|c|c|c|}
\hline \multicolumn{2}{|c|}{ Month } & \multicolumn{2}{|c|}{$\begin{array}{l}\text { Sample of All Patients } \\
\text { Discharged }\end{array}$} & \multicolumn{2}{|c|}{$\begin{array}{l}\text { Sample of Patients } \\
\text { requiring INC }\end{array}$} \\
\hline & & No. & Per cent. & No. & Per cent. \\
\hline $\begin{array}{l}\text { July } \quad \ldots \\
\text { August } \\
\text { September }\end{array}$ & $\begin{array}{l}. \\
\cdots\end{array}$ & 273 & $25 \cdot 3$ & 18 & $17 \cdot 3$ \\
\hline $\begin{array}{l}\text { October .. } \\
\text { November } \\
\text { December }\end{array}$ & $\begin{array}{l}\ldots \\
\cdots\end{array}$ & 281 & $26 \cdot 0$ & 34 & $32 \cdot 7$ \\
\hline $\begin{array}{l}\text { January ... } \\
\text { February.. } \\
\text { March ... }\end{array}$ & $\begin{array}{l}\ldots \\
\cdots\end{array}$ & 260 & $24 \cdot 1$ & 31 & $29 \cdot 8$ \\
\hline $\begin{array}{l}\text { April } \\
\text { May } \\
\text { June }\end{array}$ & $\begin{array}{l}\ldots \\
\cdots\end{array}$ & 265 & $24 \cdot 6$ & 21 & $20 \cdot 2$ \\
\hline Total .. & .. & 1,079 & $100 \cdot 0$ & 104 & $100 \cdot 0$ \\
\hline
\end{tabular}

\section{(4) Age and Sex Distribution}

Table VI shows the age and sex distribution of the sample of all patients discharged and of patients requiring INC. The proportion of patients requiring INC in each sex and age group is similar to that of all patients, indicating that INC is not required disproportionately by any one age or sex group.

\section{TABLE VI}

AGE AND SEX DISTRIBUTION OF SAMPLE OF ALL PATIENTS DISCHARGED AND PATIENTS REQUIRING INC

\begin{tabular}{|c|c|c|c|c|c|c|c|c|}
\hline \multirow{3}{*}{$\underset{\text { (yrs) }}{\text { Age }}$} & \multicolumn{4}{|c|}{ Sample of All Discharges } & \multicolumn{4}{|c|}{$\begin{array}{l}\text { Sample of Patients requiring } \\
\text { INC }\end{array}$} \\
\hline & \multicolumn{2}{|c|}{ Male } & \multicolumn{2}{|c|}{ Female } & \multicolumn{2}{|c|}{ Male } & \multicolumn{2}{|c|}{ Female } \\
\hline & No. & $\begin{array}{l}\text { Per } \\
\text { cent. }\end{array}$ & No. & $\begin{array}{l}\text { Per } \\
\text { cent. }\end{array}$ & No. & $\begin{array}{c}\text { Per } \\
\text { cent. }\end{array}$ & No. & $\begin{array}{c}\text { Per } \\
\text { cent. }\end{array}$ \\
\hline $\begin{array}{c}0-1 \\
1-14 \\
15-44 \\
45-64 \\
65+\end{array}$ & $\begin{array}{r}28 \\
81 \\
170 \\
229 \\
103\end{array}$ & $\begin{array}{r}4 \cdot 6 \\
13 \cdot 3 \\
27 \cdot 8 \\
37 \cdot 5 \\
16.9\end{array}$ & $\begin{array}{r}16 \\
63 \\
171 \\
141 \\
77\end{array}$ & & $\begin{array}{r}3 \\
4 \\
18 \\
14 \\
7\end{array}$ & $\begin{array}{r}6 \cdot 5 \\
8 \cdot 7 \\
39 \cdot 1 \\
30 \cdot 4 \\
15 \cdot 2\end{array}$ & $\begin{array}{r}2 \\
4 \\
13 \\
8 \\
2\end{array}$ & $\begin{array}{r}6.9 \\
13.8 \\
44.8 \\
27.6 \\
6.9\end{array}$ \\
\hline otal & 611 & $100 \cdot 1$ & 468 & 99.9 & 46 & 99.9 & 29 & $100 \cdot 0$ \\
\hline
\end{tabular}

(5) Diagnostic and Operation Categories of Patients Discharged and of Patients Requiring INC

Table VII shows the distribution of diagnoses amongst the sample of all patients discharged and of

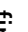


TABLE VII

DIAGNOSTIC CATEGORIES OF SAMPLE OF ALL PATIENTS DISCHARGED AND OF PATIENTS REQUIRING INC

\begin{tabular}{|c|c|c|c|c|}
\hline \multirow[t]{2}{*}{ Diagnostic Category } & \multicolumn{2}{|c|}{$\begin{array}{c}\text { Sample of All } \\
\text { Patients } \\
\text { Discharged }\end{array}$} & \multicolumn{2}{|c|}{$\begin{array}{c}\text { Sample of } \\
\text { Patients } \\
\text { requiring INC }\end{array}$} \\
\hline & No. & Per cent. & No. & Per cent. \\
\hline 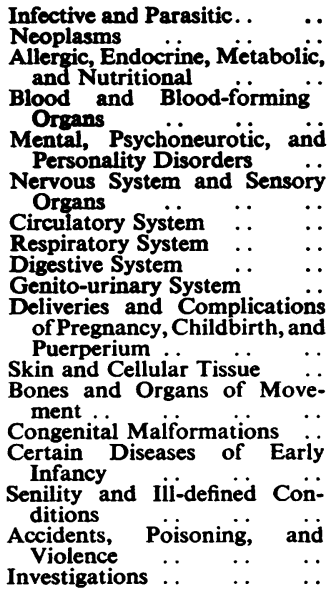 & $\begin{array}{r}2 \\
22 \\
37 \\
27 \\
0 \\
89 \\
68 \\
27\end{array}$ & $\begin{array}{r}3.0 \\
11.9 \\
3.8 \\
4.4 \\
0.9 \\
10.6 \\
10.5 \\
7.4 \\
15.8 \\
6.6\end{array}$ & $\begin{array}{l}5 \\
8 \\
6 \\
0 \\
0\end{array}$ & $\begin{array}{c}\text { - } \\
1 \cdot 3 \\
8 \cdot 0 \\
1 \cdot 3 \\
2 \cdot 7 \\
29 \cdot 3 \\
-\end{array}$ \\
\hline Total .. & 1,079 & $100 \cdot 0$ & 75 & $100 \cdot 0$ \\
\hline
\end{tabular}

patients requiring INC. From this it is evident that the major group of patients requiring INC are those admitted to hospital because of accidents, poisoning, or violence, although these represent only $6 \cdot 3$ per cent. of patients discharged. Table VIII shows the

TABLE VIII

OPERATION CATEGORIES OF SAMPLE OF ALL PATIENTS DISCHARGED AND OF SAMPLE PATIENTS REQUIRING INC

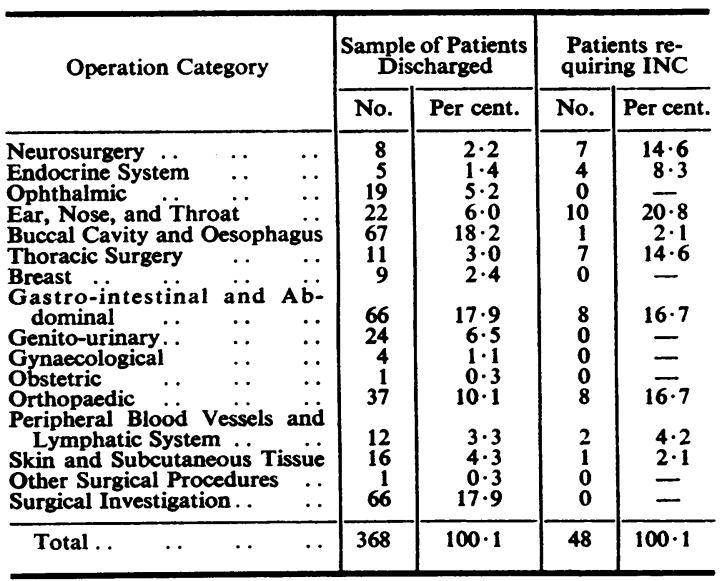

distribution of operations undergone by the sample of all patients discharged and of patients requiring INC. Patients undergoing in particular ear, nose and throat (these were all tracheostomies), neurosurgical, thoracic, and orthopaedic operations are more liable to occupy INC beds than would be expected from the proportion of such operations performed in the whole hospital. Furthermore, it is evident that INC beds are needed more often for patients undergoing surgery (64 per cent.) than for those admitted for purely medical conditions (36 per cent.).

\section{Discussion}

The Ministry of Health suggests that INC Units will be required for about 2 per cent. of medical and surgical patients and that the length of stay of patients will usually range from 1 to 2 days. The present study supports this recommendation.

The need for INC has been based on criteria evolved in 1963 and obviously may change with advances in medical and nursing techniques. The estimates are based on those patients present in the hospital during one year; obviously the needs will differ if the type of patient admitted changes. For example, if a neurosurgical unit were created at this hospital, thus increasing the proportion of beds used for this specialty in relation to total surgical beds, then the number of beds required for INC would be increased, as a much higher proportion of patients undergoing neuro-surgery require INC than do other surgical patients. From the information provided by this survey, some estimates can, however, be made if there are changes in the allocation of beds to particular specialties or if the total number of beds is changed. It must also be remembered that once an INC unit is established its advantages will be recognized and this may well lead to more extensive use than that at present envisaged.

\section{SUMMARY}

In the period July 1, 1963, to June 30,1964 , a survey was made of patients requiring INC, by dividing the hospital into five approximately equal blocks and visiting one block per day. At the same time a random 10 per cent sample was obtained of all patients discharged from the hospital. From the data it is calculated that in order to meet INC needs on 95 per cent. of all occasions, four beds would be required. Details are presented of the duration of INC in patients requiring this form of care and the categories and types of patients needing INC in relation to all patients in the hospital. 
This survey was supported by a grant from the Endowment Funds of St. Thomas' Hospital. We are most grateful to Miss T. Turner, O.B.E., for her help and encouragement, the medical and nursing staff for their co-operation throughout, and Miss V. Ovington and Miss P. Lacey for collecting and checking all the necessary forms and performing numerous calculations. Operations and diagnoses were kindly coded by the General Register Office.

\section{REFERENCE}

Ministry of Health (1962). "Progressive Patient Care". Interim Report of a Departmental Working Group. Mthly Bull. Minist. Hlth Lab. Serv., 21, 218.

\section{Statistical APPENDix}

(A) Stochastic Model

When the stochastic model was constructed, two very simple assumptions were made:

(1) The probability that a new patient will start to require intensive nursing care (INC) in the interval $\triangle t$ is $k_{1} \Delta t+0(\Delta t)$, that is, for a short time interval the probability is proportional to its length. This means that at any time there is the same probability that a new patient will be admitted who required INC or that an old patient will deteriorate and therefore require INC.

(2) The probability that a patient requiring INC will stop needing INC in the interval $\triangle t$ is $k_{2} \Delta t+0(\triangle t)$ and is therefore independent of the previous duration of need for INC. For short time interval, this probability is the same for each patient and proportional to its length. The probability includes both causes of stopping INC, i.e. death or improvement. In reality this probability differs among the patients according to some distribution. The model uses the mean of this distribution and assigns its value to all patients requiring INC. The second simplification of the real situation is the assumption of independence of the probability of stopping INC from the previous duration of INC. In fact, it is some unknown function of the duration of INC, but the agreement of calculated and observed distribution is such that this simplification can be assumed as a reasonable approach when solving the problem. With these assumptions the conditional probability, that at time $t \boldsymbol{n}$ patients will require the INC if $x$ patients did require it at time 0 is given by

$$
\begin{gathered}
\mathrm{P}(n, t ; x)=\sum_{\substack{j=0 \\
j \leqslant n}}^{x} \frac{1}{(n-j) !} \frac{k_{1}}{k_{2}}\left(1-e^{-k_{2} t}\right) n-j . \\
\exp -\frac{k_{1}}{k_{2}}\left(1-e^{-k_{2} t}\right) \cdot\left(-j^{x}\right)\left(1-e^{-k_{2} t}\right)^{x-j}\left(e^{-k_{2} t}\right)^{j}
\end{gathered}
$$

The limit distribution for $t \rightarrow \infty$ is the same for all $n$, i.e. independent of the initial state

$$
\mathrm{P}(n)=\frac{1}{n !} \frac{\left(k_{1}\right)^{n}}{k_{2}} \cdot e^{-\frac{k_{1}}{k_{2}}} \text {. }
$$

The number of patients requiring INC is thus distributed according to Poisson's Law with parameter $\frac{k_{1}}{k_{2}}$.

(B) The Problem of Sampling

During the year, one fifth of the Hospital's wards was visited each day, and the number of patients requiring INC was recorded. Thus every ward was visited at intervals of 5 days. Some patients who required INC for a longer time were recorded twice, three, four, or five times (one patient, who required INC for an extremely long time, is not counted in this calculation; he seems not to be homogenous with the rest of the patients).

From these records the distribution of duration of INC required among the patients is estimated. It is assumed that the stochastic model is valid and that the starting points of requiring INC were distributed uniformly in the 5-day intervals. This assumption is natural, because the seasonal weekly variation is smoothed by using 5-day intervals all the year. 
According to the model, a patient requiring INC in time $t=0$ will require INC in time $t$, with probability

$$
\mathrm{P}(\mathrm{INC}, t)=e^{-k_{2} t}
$$

First, an estimate of the proportion of all patients requiring INC (number of all patients $=N$ ), which was not recorded-if the duration of the INC state of a patient is equal $t<5$, then the probability that this patient will not be recorded is $1-\frac{t}{5}$. The frequency distribution of the duration of INC is $f(t)=k_{2} e^{-k_{2} t}$. Hence the combined probability element that a patient will require INC for a time $t$ and will not be observed is:

$$
d p(0, t)=\frac{5-t}{5} k_{2} e^{-k_{2} t} d t, 0 \leqslant t<5
$$

Over the interval $(0,5)$, the probability of not being observed, i.e. the proportion of not recorded patients who required INC, is:

$$
\mathrm{P}(0)=\frac{1}{5} \int_{0}^{5}(5-t) k_{2} e^{-k_{2} t} d t=1-\frac{1-e^{-5 k_{2}}}{5 k_{2}}
$$

Similarly, the proportion of all patients requiring INC, who were recorded only once is:

$$
\begin{aligned}
\mathrm{P}(1)= & \frac{1}{5} \int_{0}^{5} t k_{2} e^{-k_{2} t} d t+\frac{1}{5} \int_{5}^{10}(10-t) k_{2} e^{-k_{2} t} d t= \\
= & \frac{1}{5 k_{2}}\left[1-2\left(1+5 k_{2}\right) e^{-5 k_{2}}+(1+10) e^{-10 k_{2}}\right]+ \\
& +2\left(e^{-5 k_{2}-e^{\left.-10 k_{2}\right)}}\right.
\end{aligned}
$$

Here the second integral enumerates the proportion of INC patients with duration of INC between 5 and 10 days, who failed to be recorded twice. In the same way:

$$
\begin{aligned}
& \mathrm{P}(2)=\frac{1}{5} \int_{5}^{10}(t-5) k_{2} e^{-k_{2} t} d t+\frac{1}{5} \int_{10}^{15}(15-t) k_{2} e^{-k_{2} t} d t=
\end{aligned}
$$

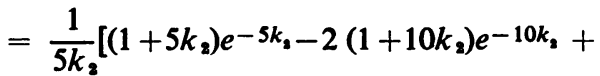

$$
\begin{aligned}
& \left.+\left(1+15 k_{2}\right) e^{-15 k_{2}}\right]+3\left(e^{-10 k_{2}}-e^{-15 k_{3}}\right)- \\
& -\left(e^{-5 k_{2}}-e^{-10 k_{2}}\right)
\end{aligned}
$$

In general:

$$
\begin{aligned}
\mathrm{P}(i)= & \frac{1}{5} \cdot \int_{\substack{5(i-1) \\
5(i+1)}}^{5 i}[t-5(i-1)] k_{2} e^{-k_{2} t} d t+\frac{1}{5} \\
& \int_{5 t}^{5}[5(i+1)-t] k_{2} e^{-k_{2} t} d t=
\end{aligned}
$$

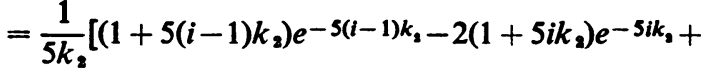

$$
\begin{aligned}
& \left.+\left(1+5(i+1) k_{2}\right) e^{-5(i+1) k_{2}}\right]+(i+1)\left(e^{-5 i k_{2}}-\right. \\
& \left.-e^{-5(i+1) k_{2}}\right)-(i-1)\left(e^{-5(i-1) k_{2}}-e^{-5 i k_{2}}\right) \text {. }
\end{aligned}
$$

\begin{tabular}{|c|c|c|c|c|}
\hline $\begin{array}{c}\text { No. of } \\
\text { Times } \\
\text { Observed }\end{array}$ & $\begin{array}{l}\text { Number } \\
\text { Observed }\end{array}$ & $\begin{array}{c}\text { Adjusted } \\
\text { No. of } \\
\text { Observations }\end{array}$ & $\begin{array}{l}\text { Observed } \\
\text { (Per cent.) }\end{array}$ & $\begin{array}{l}\text { Calculated } \\
\text { (expected) } \\
\text { (Per cent.) }\end{array}$ \\
\hline $\begin{array}{l}1 \\
2 \\
3 \\
4 \\
5 \\
6 \\
7 \\
8\end{array}$ & $\begin{array}{r}61 \\
8 \\
2 \\
2 \\
1 \\
0 \\
0 \\
1\end{array}$ & $\begin{array}{r}61 \\
8 \\
2 \\
2 \\
1 \\
- \\
-\end{array}$ & $\begin{array}{c}82 \cdot 43 \\
10 \cdot 84 \\
2 \cdot 70 \\
2 \cdot 70 \\
1 \cdot 35 \\
= \\
-\end{array}$ & $\begin{array}{c}82.42 \\
14.57 \\
2.55 \\
0.45 \\
0.01 \\
= \\
=\end{array}$ \\
\hline Total .. & 75 & 74 & 99.99 & $100 \cdot 00$ \\
\hline
\end{tabular}

The proportion of at least once recorded patients requiring $\mathrm{INC}$ is:

$$
\sum_{i=1}^{\infty} \mathrm{P}(i)=\frac{1-e^{-5 k_{2}}}{5 k_{2}}-1=p(0)
$$

The percentages of the total sum of recorded patients are therefore:

$$
\begin{aligned}
& P_{1}=\frac{P(1)}{1-P(0)}= \\
& =\frac{1}{1-e^{-5 k_{2}}}\left[1-2\left(1+5 k_{2}\right) e^{-5 k_{1}}+\right. \\
& \left.+\left(1+10 k_{2}\right) e^{-10 k_{2}}+10 k_{2}\left(e^{-5 k_{2}}-e^{-10 k_{2}}\right)\right] \\
& \mathbf{P}_{2}=\frac{\mathbf{P}(2)}{1-\mathbf{P}(0)}= \\
& =\frac{1}{1-e^{-5 k_{2}}}\left[\left(1+5 k_{2}\right) e^{-5 k_{2}}-2\left(1+10 k_{2}\right) e^{-10 k_{2}}+\right.
\end{aligned}
$$

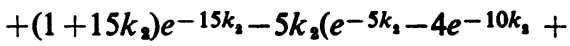

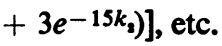

Generally $\mathrm{P} i=\frac{\mathrm{P}(i)}{1-\mathrm{P}(0)}$

The recorded distribution is given in the following Table:

One case, which was recorded eight times, seems very exceptional and therefore was excluded. When estimating the value $k_{2}$, the formula for $\mathrm{P}_{1}$ was used and fitted the value $k_{2}=0.348$ for the best agreement. As is seen from the above Table, the agreement is quite good in the first three rows, the tail of the recorded distribution is slightly different, which is caused by the heterogeneity of patients' states, which has not been counted in the model.

Taking the "working" number of recorded patients as $n=74$, one can estimate the total number 
$N$ of all patients requiring $\mathrm{NC}$ from the equation:

$$
n=N .(1-\mathrm{P}(0))=N \frac{1-e^{-5 k_{2}}}{5 k_{2}}
$$

Thus:

$$
N=\frac{n .5 k_{8}}{1-e^{-5 k_{2}}}
$$

and with $k_{2}=0.348$

$$
N=74 \frac{1 \cdot 74}{1-0 \cdot 1757}=74 \times 2 \cdot 11=156
$$

If the one eliminated patient is included, the estimate becomes $N=157$. Therefore our sample comprised $100 \times 75 / 157=47.8$ per cent. of all patients requiring INC, and all patients, who failed to be recorded, required INC for less than 5 days. When comparing their number with the 10 per cent. sample of all discharged patients, we find that it is equal to $100 \times 157 / 10790=1.455$ per cent. of all patients discharged during one year.

As a result, the frequency distribution of duration $t$ of INC, which has the form

$$
f(t)=k_{2} e^{-k_{2} t} \text { is equal to } 0 \cdot 348 e^{-0 \cdot 348 t} \text {, }
$$

where $t$ is given in day-units. From this the classinterval distribution for intervals of 1-day length is found and used for estimating the number of beds required for INC.

\begin{tabular}{c|c|c}
\hline $\begin{array}{c}\text { Time Interval } \\
\text { (days) }\end{array}$ & Percentage & $\begin{array}{c}\text { Bed Required } \\
\text { for } n \text { Days }\end{array}$ \\
\hline $0-1$ & $29 \cdot 39=\left(1-e^{-k_{1}}\right)$ & 1 \\
$1-2$ & $20 \cdot 76=\left(e^{-k_{2}}-e^{-2 k_{2}}\right)$ etc. & 2 \\
$2-3$ & $14 \cdot 64$ & 3 \\
$3-4$ & 10.64 & 4 \\
$4-5$ & 7.02 & 5 \\
$5-6$ & $5 \cdot 16$ & 6 \\
$6-7$ & 3.64 & 7 \\
$7-8$ & 2.63 & 8 \\
$8-9$ & 1.76 & 9 \\
$9-10$ & 1.28 & 10 \\
$10-11$ & 0.91 & 11 \\
$11-12$ & 0.63 & 12 \\
$12-13$ & 0.46 & 13 \\
$13-14$ & 0.33 & 14 \\
$14-\infty$ & 0.75 & 15 \\
\hline
\end{tabular}

The number of bed-days required was

$$
\begin{gathered}
N \sum_{i=1}^{\infty} i\left(e^{-(i-1) 0 \cdot 348}-e^{-i 0 \cdot 348}\right)=N \sum_{i=0}^{\infty} e^{-0 \cdot 348 i}= \\
=\frac{N}{1-e^{-0 \cdot 348}} .
\end{gathered}
$$

When $N=157$ :

$$
\text { Number of bed-days }=\frac{157}{0 \cdot 2939}=534 .
$$

So, a daily average is $\frac{534}{366}=1 \cdot 459$.

But this average is slightly misleading. If the time a bed is required is a continuous variable, then the bed $\times$ time in days is equal to

$$
N \int_{0}^{\infty} t k_{2} e^{-k_{2} t} d t=\frac{N}{k_{2}}
$$

and in our situation - bed $\times$ time $=\frac{157}{0 \cdot 348}=451$.

The mean duration of INC is then, according to this model, equal to:

$$
\bar{t}=\int_{0}^{\infty} t k_{2} e^{-k_{2} t} d t=\frac{1}{k_{2}}=\frac{1}{0 \cdot 348}=2 \cdot 874,
$$

and the standard deviation equal to:

$$
\begin{aligned}
\sigma_{t} & =\left[\int_{0}^{\infty} t^{2} k_{2} e^{-k_{2} t} d t-\frac{1}{k_{2}^{2}}\right]^{\frac{1}{2}}=\sqrt{\frac{2}{k_{2}^{2}}-\frac{1}{k_{2}^{2}}}= \\
& =\frac{1}{k_{2}}=2 \cdot 874 .
\end{aligned}
$$

The first figure for required bed-days - 534-is more appropriate from an administrative point of view, when a bed-day means that a bed was occupied for some part of one day. The second figure -451 expresses the total estimated duration of $\mathrm{NC}$ in one year, so that the daily average complying with the mean of the Poisson distribution in section $\mathbf{A}$ is:

$$
\frac{451}{366}=1 \cdot 232=\hat{\lambda}=\frac{k_{1}}{k_{2}}
$$

From this result the constant $k_{1}$ of the stochastic model is found to be

$$
k_{1}=1 \cdot 232 \times 0 \cdot 348=0.429
$$

On the assumption of the above distribution and the way of sampling, the expected percentages of 74 recorded patients according to the duration of need for INC for one-day intervals are given by

$$
\begin{aligned}
\mathbf{P}_{i}= & 100 \cdot\left[\int_{i-1}^{i} \frac{t}{5} k_{2} \cdot e^{-k_{2} t} d t\right] \div\left[\frac{1-e^{-5 k_{2}}}{5 k_{2}}\right]== \\
= & 100 \cdot \frac{1+(i-1) k_{2}-\left(1+i k_{2}\right) e^{-k_{2}}}{1-e^{-5 k_{2}}} \cdot e^{-(i-1) k_{2}}, \\
& \text { for } i=1,2,3,4,5
\end{aligned}
$$


and

$$
\begin{aligned}
\mathbf{P}_{i}= & 100 \cdot\left[\int_{i-1}^{i} k_{2} e^{-k_{2} t} d t\right] \div\left[\frac{1-e^{-5 k_{2}}}{5 k_{2}}\right] \\
= & 100 \cdot \frac{\left(1-e^{\left.-k_{2}\right)} \cdot 5 k_{2}\right.}{1-e^{-5 k_{2}}} \cdot e^{-(i-1) k_{2}} \\
& \text { for } i=6,7, \ldots \ldots
\end{aligned}
$$

In the following Table these percentages are calculated for $k_{2}=0 \cdot 348$. The expected numbers of patients totalling to 74 are rounded to integers. After the addition of the one deleted patient, the most

\begin{tabular}{|c|c|c|c|}
\hline $\begin{array}{c}\text { Time Interval } \\
\text { (days) }\end{array}$ & $\begin{array}{l}\text { Expected } \\
\text { Percentages }\end{array}$ & $\begin{array}{l}\text { Expected } \\
\text { Numbers of } \\
\text { Patients } \\
\text { (rounded to } \\
\text { integers) }\end{array}$ & $\begin{array}{c}\text { The Most Likely } \\
\text { Distribution } \\
\text { (in } \\
\text { percentages) }\end{array}$ \\
\hline $\begin{array}{l}0-1 \\
1-2 \\
2-3 \\
3-4 \\
4-5 \\
5-6 \\
6-7 \\
7-8 \\
8-9 \\
9-\infty\end{array}$ & $\begin{array}{r}5 \cdot 84 \\
12 \cdot 89 \\
15 \cdot 28 \\
15 \cdot 16 \\
13 \cdot 79 \\
10 \cdot 89 \\
7 \cdot 68 \\
5 \cdot 55 \\
3 \cdot 71 \\
9 \cdot 21\end{array}$ & $\begin{array}{c}4 \\
9 \\
12 \\
11 \\
10 \\
8 \\
6 \\
4 \\
3 \\
7(+1)^{*}\end{array}$ & $\begin{array}{r}5 \cdot 33 \\
12 \cdot 00 \\
16 \cdot 00 \\
14 \cdot 67 \\
13 \cdot 33 \\
10 \cdot 67 \\
8 \cdot 00 \\
5 \cdot 33 \\
4 \cdot 00 \\
10 \cdot 67\end{array}$ \\
\hline Total $\ldots$ & $100 \cdot 00$ & $74(+1)^{*}$ & $100 \cdot 00$ \\
\hline
\end{tabular}
likely occurring distribution in the sample of 75 patients is given in percentages.

* the deleted patient

From our results given by now, we may conclude that the number of beds occupied by patients requiring INC is distributed according to Poisson's Law with probabilities

$$
\mathrm{P}(n)=\frac{1}{n !} \cdot 1 \cdot 232^{n} e^{-1 \cdot 232}
$$

The probabilities in percentages and the expected numbers of days when $x$ beds are required are:

\begin{tabular}{c|c|c}
\hline Beds Required & Percentage & $\begin{array}{c}\text { Expected Days } \\
\text { in 1 Year }\end{array}$ \\
\hline 0 & $29 \cdot 17$ & 106.76 \\
1 & 35.94 & 131.54 \\
2 & 22.14 & 81.03 \\
3 & 9.09 & 33.27 \\
4 & 2.80 & $10 \cdot 25$ \\
5 & 0.69 & 2.53 \\
6 & 0.14 & $0 \cdot 51$ \\
7 and More & 0.03 & 0.11 \\
\hline Total $\quad . \quad \ldots$ & 100.00 & 366.00 \\
\hline
\end{tabular}

From the Table it is obvious that five beds for INC will be used on two days. But this conclusion is made on the basis of a "smoothed" model without taking into account some long cases requiring INC for a long time, so that perhaps occasionally even more than six beds may be required.

During the year one fifth of all patients were checked each day and the number of patients requiring INC was recorded. Assuming that all five blocks are approximately of the same size and with the same type of patients, the distribution of number of patients requiring INC should also be of the Poisson type with parameter

\begin{tabular}{|c|c|c|c|c|}
\hline $\begin{array}{l}\text { Beds } \\
\text { Required }\end{array}$ & $\begin{array}{c}\text { Expected } \\
\text { Percentage }\end{array}$ & $\begin{array}{l}\text { Expected } \\
\text { Number } \\
\text { of Days }\end{array}$ & $\begin{array}{l}\text { Recorded } \\
\text { Number } \\
\text { of Days }\end{array}$ & $\begin{array}{c}\text { Expected } \\
\text { by Fitting } \\
\text { a Poisson } \\
\text { Distri- } \\
\text { bution }\end{array}$ \\
\hline $\begin{array}{c}0 \\
1 \\
2 \\
3 \text { and More }\end{array}$ & $\begin{array}{r}78 \cdot 16 \\
19 \cdot 26 \\
2 \cdot 37 \\
0 \cdot 21\end{array}$ & $\begin{array}{r}286 \cdot 07 \\
70 \cdot 49 \\
8 \cdot 67 \\
0 \cdot 77\end{array}$ & $\begin{array}{r}285 \\
61 \\
17 \\
3\end{array}$ & $\begin{array}{r}273 \cdot 22 \\
79 \cdot 86 \\
11 \cdot 68 \\
1 \cdot 24\end{array}$ \\
\hline Test of Agreement & \multicolumn{2}{|c|}{$\begin{array}{c}\chi^{2}=15.74(4 d . f .) \\
P<0.01\end{array}$} & \multicolumn{2}{|c|}{$\begin{aligned} x^{2}=9.88(3 d . f .) & =0.05\end{aligned}$} \\
\hline
\end{tabular}

$$
\lambda=\frac{1}{5} \frac{k_{1}}{k_{2}}=1 \cdot 232 / 5=0 \cdot 2464 .
$$

In the next Table the observed and the computed expected frequencies are presented:

The agreement of expected and recorded frequencies is not satisfactory, the tail of the recorded distribution is longer than that of the Poisson distribution. Even frequencies calculated for $\lambda=$ 0.2923 (the calculated mean) are not in good agreement (the last column), $\chi^{2}$ is still significant at the 5 per cent. level.

Nevertheless, the distribution found is very similar to the Poisson distribution which was produced on the basis of a very simple stochastic model. It seems that the real situation is more complex, and does not exactly fit a Poisson distribution. The resulting distribution may be assumed to be a weighted average of many Poisson distributions with different intensities, where the differences may be caused by, for example, seasonal variation or heterogeneity of the cases observed. A negative binomial distribution often results, allowing for a longer tail. (In our case a negative binomial distribution provides a better fit for the recorded frequencies.) Higher frequencies at the tail of the recorded distribution show that the number of beds required may here be higher than that indicated by the Poisson distribution. Therefore, and also because of seasonal variation of the parameter

$$
\lambda=\frac{k_{1}}{\mathbf{k}_{2}}
$$

on the data examined the number of beds available should be about eight to be sure that no patient will fail to receive proper care at any time. 